\title{
El filosofar de Estanislao Zuleta y el marxismo
}

Indudablemente, aquellos que piensan que la filosofía es una privilegiada actividad exclusiva de los nacidos y criados al norte del Mar Mediterráneo o del Rio Bravo pueden poner en duda que Estanislao Zuleta haya sido propiamente un filósofo, tal vez porque dada su formación autodidacta no podía colgar en la pared de su casa un título de Doctor en Filosofía de una prestigiosa universidad.

Así de ingrata es la vida académica, pues suele atribuírseles sin recato dicha condición a algunos que ostentan tales títulos, pero jamás han podido aproximarse al rigor y la profundidad del filosofar (Zuleta, 1995, 
pp. 25-26) ${ }^{162}$ del pensador colombiano, que consagró su heterodoxa vida intelectual a pensar con cabeza propia (Guadarrama, 2012, p. 461). ${ }^{163}$

Esto no significa que no hayan influido sobre él numerosos filósofos y escritores - estudiados por otros investigadores- entre los cuales Marx tendría un lugar especial.

Aunque el objetivo del presente texto no es fundamentar por qué razón la obra de Zuleta puede considerarse entre las mejores expresiones del pensamiento filosófico latinoamericano contemporáneo, debe partirse del presupuesto de su alta estimación de la praxis del filosofar, tal vez inspirado en el kantiano criterio de que el verdadero maestro no debe enseñar a sus discípulos filosofía, sino enseñarlos a filosofar. Además, no reducía las misiones de la filosofía al ámbito académico, sino que le otorgaba mayor trascendencia en todos los espacios de la sociedad humana. De ahí que sostuviese "Creo que

162 "Entiendo por filosofía la posibilidad de pensar las cosas, de hacer preguntas, de ver contradicciones. Asumo el concepto de filosofía en un sentido muy amplio, en el sentido griego de amor a la sabiduría. Es un filósofo el hombre que quiere saber; el hombre que aspira a que el saber sea la realización de su ser; el hombre que quiere saber por qué hace algo, para qué lo hace, para quien lo hace; el hombre que tiene una exigencia de autonomía. El hombre que está inscrito en una búsqueda de universalidad es también un filósofo, así como aquel que quiere ser consecuente con los resultados de su investigación." Zuleta, E. Educación y democracia. Un campo de combate, Corporación Tercer Milenio-Fundación Estanislao Zuleta, Bogotá, 1995, pp. 25-26.

163 "Pensar con cabeza propia no significa asumir posturas de chauvinismo epistémico y cerrarse a los aportes del pensamiento provenientes de cualquier parte del mundo. Tampoco presupone desconocer el valor intelectual o de otro carácter de pensadores con los cuales se puede, incluso, coincidir parcial o totalmente. Por el contrario, significa asumirlos, pero no indiferenciadamente, sino en correspondencia con las exigencias cognoscitivas, axiológicas e ideológicas que cada momento reclama. Se han de medir con mayor rigor los grados de autenticidad de dicho pensamiento que los de originalidad, si por tal solamente se entiende su carácter novedoso. Este ejercicio para evidenciar mayoría de edad intelectual, presupone pensar asumiendo como propias las ideas más adecuadas sin preocuparse demasiado por su procedencia. No debe importar si está vinculada o no a alguna lectura previa o es el producto absolutamente individual del último que la revela. En definitiva, todo pensamiento posee siempre una soterrada entraña social, aunque sus obstetras no pierdan mérito por su cuota de originalidad en el parto intelectual de cada idea”. Guadarrama, P. Islas. Revista de la Universidad Central "Marta Abreu” de Las Villas, Santa Clara, N. 121, julio-septiembre, 1999, p. 133; Pensamiento Filosófico Latinoamericano. Humanismo, método e historia, Universitá degli Studi di Salerno-Universidad Católica-Planeta, Bogotá, tomo II, 2012. p. 461. 
la filosofía siempre que estuvo viva fue algo más que docencia y recuento de ideas. Fue vigilancia crítica, territorio del debate, impulso a la fecundidad del pensamiento" (Zuleta, 2011, p. 37).

Poseía una alta estimación de la filosofía, pues exaltaba su pretensión omnicomprensiva y universalizadora del saber, lo que la diferenciaba sustancialmente de las ciencias, el arte, las tecnologías y el saber común. "En lugar de desear una filosofía llena de incógnitas y preguntas abiertas -sostenía- queremos poseer una doctrina global, capaz de dar cuenta de todo, revelada por espíritus que nunca han existido o por caudillos que desgraciadamente sí han existido" (Zuleta, 2011, p.13).

La filosofía era para Zuleta un instrumento indispensable no solo para pensar críticamente, sino para orientar la praxis transformadora de la realidad que le corresponde vivir a cada pensador, y de ahí su alta estimación de la obra de Marx, aunque tal vez no tanta de los proclamados o autoclasificados como marxistas.

Zuleta destacó la necesidad de cultivar la filosofía, la construcción teórica y en particular la lógica, especialmente en los momentos en que las distintas formas de práctica lo exigen en determinadas situaciones históricas. A su juicio, "Es muy frecuente en la historia del pensamiento encontrar ese retorno sobre los principios, las categorías, las operaciones, las premisas e implicaciones del trabajo del pensamiento, cuando se produce una crisis en la acción, que lleva a pensar que la teorización y la explicación efectiva, se habían desarrollado hasta entonces con una lógica deficiente." (Zuleta, 2003, p. 24).

Por tal motivo estimó en alto grado la labor teórica no solo de Marx y Engels, sino también la de sus más significativos seguidores, entre los que destacó a Lenin. En ese sentido apuntaba que:

Es muy diciente, por ejemplo, el hecho de que Lenin, quien estaba embarcado desde muy temprano en su vida en trabajos políticos, teóricos y económicos, directamente relacionados con estudios acerca del desarrollo del capitalismo en Rusia, de las condiciones generales de la lucha de clases, de la teoría del partido, etc., al ser rudamente golpeado y encontrarse asombrado y desconcertado por el acontecimiento como la Primera Guerra Mundial, hubiera reaccionado dedicándose a leer la Ciencia de la Lógica de Hegel. (Zuleta, 2011, p. 24). 
Zuleta admiró mucho la rigurosidad lógica del pensamiento de Marx que le ha significado ser considerado entre los más destacados filósofos de todos los tiempos, aun cuando en algunos de sus análisis juveniles hubiese, como cualquier mortal, incurrido en anfibologías (Zuleta, 2003, p. 229) ${ }^{164}$ y otras imprecisiones que en su madurez intelectual superó con creces.

Ahora bien, la tarea principal del presente capítulo consiste en analizar algunas de sus valoraciones sobre el pensador alemán, a diferencia de lo que se ha dado a conocer con el polisémico patronímico de marxismo independientemente, al referirse al marxismo por lo regular, aunque no siempre se refiriese específicamente a la obra de Marx (Zuleta, 2008, p. 148). ${ }^{165}$

Sin embargo en otras ocasiones Zuleta distinguía adecuadamente entre Marx y los marxistas, con determinados análisis, como al considerar que "La idea de la racionalidad capitalista la deberíamos tomar con mucho cuidado. Los marxistas — excepto Marx - como por ejemplo Lenin, Trotsky, y otros que ya sería un poco complicado llamar marxistas como Stalin, la confunden con frecuencia con la racionalidad. Por lo demás han reprimido de El Capital los capítulos XII División del trabajo y manufactura y XIII (Maquinaria y gran industria). Lo que Marx reprocha al capitalismo no es solamente que sea irracional, sino su tipo particular de racionalidad" (Zuleta, 2008, p. 107).

164 "Entre los marxistas también se pueden encontrar casos muy notables de anfibologías. Ranciere muestra por ejemplo como el mismo Marx cometió anfibologías en algunas obras de su juventud. El concepto de obrero es utilizado en algunos textos en un sentido nítidamente económico para referirse a quien carece de medios de producción y vende su fuerza de trabajo por un salario. Pero en el mismo contexto la palabra "obreros" hace alusión al creador, al productor y al hombre en general. Posteriormente -sobre todo en las obras de madurez- Marx resultó ser uno de los más finos detectores de anfibologías. En la moderna crítica marxista, así como la crítica que hace Kant de las pruebas de existencia de Dios, se emplea con mucha frecuencia el criterio de búsqueda de anfibologías para detectar en un argumento si un mismo concepto se está empleando en un mismo sentido o en varios sentidos a la vez." Zuleta, E. Lógica y crítica. Lecciones de filosofía, Hombre Nuevo Editores, Medellín, 2003, p. 229

165 "En el marxismo, y cuando yo hablo de marxismo generalmente me refiero al marxismo de Marx, había una idea del proletariado que probablemente es idealizada: el proletariado como gran filósofo, como sujeto de la historia, como liberador de la humanidad, como clase revolucionaria hasta el fin". Zuleta, E. Conversaciones con Estanislao Zuleta, Hombre Nuevo Editores EU, Medellín, 2008, p. 148. 
De manera que, de antemano, se presenta un obstáculo epistemológico -diría Bachelard- consistente en tratar de precisar adecuadamente la especificidad de sus análisis sobre Marx y diferenciarlos del de Engels o Lenin (Zuleta, 1987, p. 70);166 así como de algunos de sus discípulos o de los marxólogos, presuntamente no comprometidos desde el punto de vista ideológico (Zuleta, 1987, p. 191). ${ }^{167} \mathrm{Si}$ algo diferenció sustancialmente a Zuleta de estos últimos fue no solo su profundo rigor intelectual desentrañador de nuevos análisis teóricos, sino también su definido compromiso ideológico — del mismo modo que lo había estimado altamente en Marx (Zuleta, 1987, p. 16) ${ }^{168}$ -

166 "Si dejamos de lado el precario determinismo de Engels y Lenin y volvemos al pensamiento de Marx, encontraremos una concepción completamente diferente de la historia, de la revolución, y por lo tanto, una nueva idea del partido revolucionario". Zuleta, E. Ensayos sobre Marx, Percepción, Medellín, 1987, p. 70.

167 "Parafraseando podría decirse que hay algo peor que el marxismo vulgar, y es el marxismo profesoral. Aquí todas las tesis pueden ser admitidas y sopesadas con máxima ecuanimidad, precisamente porque se descarta de antemano que puedan convertirse en luchas reales. Toda pasión por construir un mundo nuevo ha desaparecido lo mismo que toda indignación por la infamia de la vida capitalista, tanto de su miseria como de su riqueza, de sus derrotados como de sus exitosos. Al contrario puede abandonarse todo romanticismo revolucionario y toda utopía. El soñador ha entrado al fin en la edad de la razón, se ha instalado sólidamente en la realidad y puede estar seguro de que su nueva disciplina, la marxología científica, es una especialidad bastante rentable en el capitalismo". Zuleta, E. Ensayos sobre Marx, Percepción, Medellín, 1987, p. 191.

168 "Me parece que el pensamiento de Marx es al mismo tiempo un análisis y una crítica de lo que está ocurriendo. Él no lo oculta nunca. Nunca se las dio de neutral. No dijo: soy un científico y por lo tanto no tomo partido. Eso no lo encontrarán ustedes jamás en Marx. Se considera un científico y por lo tanto toma partido. La idea del científico que no tiene nada que ver con lo que pasa, que es un testigo neutral, no es una idea marxista, Marx toma partido y muy claramente. Ahora bien, Marx no toma partido, propiamente hablando a nombre de una moral, es decir, de una idea del hombre por fuera de la historia, de un deber ser del hombre. Por ejemplo en la Sagrada Familia dice: los comunistas no predicamos ninguna moral, no oponemos el altruismo al egoísmo, no oponemos la buena voluntad y el interés público al interés privado. Nosotros nos oponemos a un mundo en el cual los individuos necesariamente oponen el altruismo al egoísmo y defienden sus intereses privados. Es a ese mundo al que nos oponemos. No es que opongamos dentro de ese mundo un bien contra un mal". Idem. p. 16 
contra el capitalismo (Zuleta, 2008, pp. 107-108) ${ }^{169}$ y la lucha por lograr una sociedad mucho más humana.

Sus análisis sobre el capitalismo se distanciaban de aquellos que se limitan al estudio de sus mecanismos económicos, tecnológicos, financieros, ideológicos, entre otros, pues le interesaba, sobre, todo una mejor comprensión filosófica de sus rasgos esenciales en una perspectiva humanista y cultural

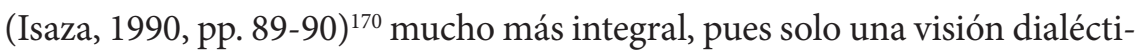
ca, sistémica e integral del capitalismo posibilitaría combatirlo de la misma forma y no por parcelas desarticuladas entre sí.

Para tratar de superar esos obstáculos y realizar tal estudio resulta de utilidad tomar en cuenta lo que podría considerarse el núcleo duro de la teoría marxista. ${ }^{171} \mathrm{~A}$ partir de este criterio metodológico es posible realizar el

169 "De esta manera el capitalismo se preocupa por el incremento de la productividad del trabajo (en términos de Marx de la producción de plusvalía relativa) - y moviliza la ciencia para ello- porque la productividad del trabajo es un elemento esencial de la valoración del capital; pero no se preocupa por lo que pueda ocurrirles a los trabajadores mismos, a los que quedan cesantes, a los consumidores, o a otros sectores de la vida social. Quiero insistir sobre este último punto porque lo importante del análisis de Marx en el capital no consiste en haber descubierto - como creímos mucho tiempo y como él mismo creyó- la determinación de la vida política y social por la economía sino haber descubierto que la sociedad capitalista - y solo en ella- la economía se autonomiza, adquiere sus propias leyes, completamente indiferentes a su efecto sobre las otras instancias, niveles e instituciones de la vida social." Zuleta, E. Conversaciones con Estanislao Zuleta. Hombre Nuevo Editores EU. Medellín. 2008, pp. 107-108.

170 "Su visión del marxismo fue siempre cultural, con un enfoque universal. Sus análisis sobre el capitalismo jamás cayeron en descripciones contables, propias del pensamiento tecnomorfo". Isaza, G. "Estanislao Zuleta: Un pensador solitario", en G. Bustamante, J. García, F. Giraldo et al. Estanislao Zuleta (1935-1990), Ediciones la Rana y el Águila, Tunja, 1990, pp.89-90.

171 "Ya en ocasión anterior pretendimos precisar también algunos de los elementos componentes esenciales del posible "núcleo duro" del marxismo al indicar "el carácter científico de sus explicaciones acerca de las leyes fundamentales que rigen el desarrollo de la historia y en especial de la sociedad capitalista. El esclarecimiento de los factores que intervienen en el proceso de producción de la conciencia humana, el lugar de la práctica en la teoría del conocimiento, el despliegue de las leyes objetivas que rigen las formaciones económico-sociales, en especial, la dialéctica de la correlación entre las fuerzas productivas y las relaciones de producción; la adecuada significación de la determinación de los elementos de carácter económico en su correlación con la divergente y dinámica acción de las formas de la conciencia social; el papel impulsor de la lucha de cla- 
análisis diferenciado sobre la relación de Zuleta con Marx y con el marxismo, pues a pesar de su manifiesta identificación, también supo plantear debidamente lo que consideraba algunos de sus errores, como la idealización de la presunta misión histórica del proletariado (Zuleta, 2008, p. 147) ${ }^{172}$ En ese sentido declaraba, "Yo no creo que el marxismo de Marx sea una teoría de la sociedad válida en su totalidad. Yo he defendido la teoría del valor, pero no creo por ejemplo que la teoría del proletariado sea correcta"(Zuleta, 2008, p. 145).

El hecho de que Zuleta no estuviese de acuerdo con Marx en relación con el protagonismo de la clase obrera, así como en otras cuestiones, como en la visión teleológica sobre la evolución del dinero (Zuleta, 1972, p. 81) ${ }^{173}$ no significa que no coincidiera con los principales elementos que caracterizan el núcleo duro de la concepción materialista de la historia, y mucho menos que por tal

ses, conducente a través de la revolución social hacia una sociedad que emprende la eliminación de los antagonismos de clases; los mecanismos de enajenación que reproduce la sociedad capitalista con el básico objetivo de la mayor obtención de plusvalía, constituyen algunos de los principales componentes de lo que podría considerarse el núcleo duro de la teoría marxista, atendiendo a su trascendencia y validez universalmente reconocida. Por supuesto que dentro de cada uno de esos elementos es posible e imprescindible delimitar un sinnúmero de ideas que, a su vez, desempeñan un papel fundamental que si no están presentes, hay razones suficientes para dudar del posible carácter marxista de lo que se plantea o al menos, de sus puntos de coincidencia fundamentales con las tesis esenciales de aquel Prometeo de Tréveris". Guadarrama, P. "El núcleo duro de la teoría marxista y su afectación por la crisis del socialismo”, En América Latina, marxismo y postmodernidad, Universidad INCCA de Colombia, Bogotá, 1994, pp. 204-205; Humanismo, marxismo y postmodernidad, Editorial Ciencias Sociales, La Habana, 1998, pp. 249-250; Islas, Revista de la Universidad Central "Marta Abreu” de Las Villas, Santa Clara, No. 108, mayo-agosto 1994, pp. 32-33.

172 "En el marxismo hay algunos errores teóricos que debemos tener en cuenta. En primer lugar, desde El manifiesto comunista, hasta la última frase del primer tomo de El capital, y en muchos otros textos, hay evidentemente en Marx una idealización del proletariado". Zuleta, E. Conversaciones con Estanislao Zuleta. Hombre Nuevo Editores EU, Medellín, 2008, p. 147.

173 "Las afirmaciones de Marx sobre el desarrollo del dinero están en este punto impregnadas de evolucionismo, y en contradicción con su pensamiento, pues él mismo ha demostrado que en la historia no hay una evolución de categorías en forma lineal". Zuleta, E. Comentarios a la Introducción a la crítica de la economía política (Manuscritos de 1857). Apéndice. Sobre la teoría del reflejo, Universidad de Antioquia, Medellín, 1972, p. 81. 
motivo no se le deba considerar propiamente un marxista. En verdad, tal vez con razón —como plantea Alberto Valencia (1996, p. 134)— ${ }^{174}$ lo fue mucho más que algunos autotitulados como tales, pero que se subordinaron al escolástico principi autoritatis en lugar de asumir una postura dialéctica y, por tanto, crítica, como supieron hacer en momentos diferentes José Carlos Mariátegui, (Guadarrama, 1996, pp. 109-117), Antonio García Nosa (Guadarrama, 2006, pp. 19-80) o Ernesto Che Guevara (Guadarrama, 2005, pp. 40-47).

En primer lugar, Zuleta destacó la superación epistemológica que produjo Marx - aun cuando esta se realizara bajo la influencia de dos de los más grandes "idealistas inteligentes", de acuerdo con Lenin, de todos los tiempos, como lo fueron Kant y Hegel- respecto a las concepciones materialistas, pero contemplativas que le habían antecedido. En tal sentido, acertadamente consideró "Todo el materialismo anterior a Marx para poder hacer del conocimiento algo posterior al objeto conocido y del objeto conocido algo independiente de su conocimiento, hace del conocimiento un fenómeno pasivo, un fenómeno de registro" (Zuleta, 1987, p. 156).

Con razón sostiene que Marx había producido no solo un extraordinario descubrimiento científico al desenmascarar el papel de la plusvalía, sino que a la vez había producido un salto cualitativo en el desarrollo de la lógica dialéctica (Zuleta, 1972, p. 53), ${ }^{175}$ en verdad había producido una revolución

174 "Zuleta era pues un pensador marxista en el mejor sentido filosófico que esta denominación haya podido tener en el pasado o pueda llegar a tener en un futuro inmediato [...]."Valencia, A. En el principio era la ética... ensayo de interpretación del pensamiento de Estanislao Zuleta, Universidad del Valle, Cali, 1996, p. 134.

175 “(...) el problema es saber por qué la plusvalía no puede presentarse sino en las diferentes formas de la ganancia, adheridas a diferentes formas materiales o personales. El movimiento del pensamiento de Marx no consiste únicamente en desprenderse de la apariencia para llegar por medio del análisis a una unidad interior esencial, sino en mostrar por qué la apariencia como apariencia es necesaria, en qué medida el hecho de que se presente así es un síntoma de la lógica interna del proceso estudiado, Este ir y venir, ir de la apariencia a los fundamentos y luego volver para mostrar los fundamentos de la apariencia misma y su necesidad, es una de las formas de lo que podría llamarse la dialéctica de Marx, dialéctica específica, nueva, que no contiene nada de la vieja dialéctica metafísica de Hegel Cuando Marx emplea aquí la palabra contradicción lo hace con el significado de error, pues qué otra cosa que un error puede ser el intentar una reducción de conceptos sin el establecimiento de eslabones intermedios, es decir, sin un proceso de demostración riguroso." Zuleta, E. Comentarios a la Introducción a la crítica 
filosófica, de lo cual no debe derivarse que haya sido la primera ni la última en la historia. Pero lo importante es que destaca que no solo aportó a la ciencia en el desentrañamiento de la intríngulis de una formación económico-social tan compleja como el capitalismo, sino que enriqueció la filosofía y en particular la lógica dialéctica al plantear una novedosa compresión del proceso de ascenso de lo abstracto a lo concreto (Zuleta, 1972, p. 69) ${ }^{176}$, así como el analizar entre el concepto de estructura (Zuleta, 1972, p. 57), y la correlación e interdependencia que la misma produce entre el consumo, las necesidades y la producción. Por ese motivo sostiene que: "Marx está produciendo por primera vez, por lo menos de una manera desarrollada y aplicada a un objeto especificado, Marx produce un nuevo concepto de causalidad que no es aristotélico [...] La causalidad de Marx tampoco es reductible a la de los mecanicistas del siglo xviii que se reducían a aplicar el concepto de causa eficiente; ni tampoco a ciertos sensualismo y materialismo vulgar que hacían la reducción a la causa material. En Marx se trata de producir un concepto nuevo de causalidad que los abarca a todos y los reinterpreta a todos, Marx significa una revolución en lógica y en filosofía [...]" (Zuleta, 1972, p. 37).

de la economía política (Manuscritos de 1857) Apéndice; Sobre la teoría del reflejo. Universidad de Antioquia, Medellín. 1972. p. 53.

176 "En Marx el proceso de conocimiento se plantea como un elevarse de lo abstracto a lo concreto Pero no se crea que se trata de una simple inversión del método empirista. Los términos abstracto y concreto sufren en la concepción de Marx una reelaboración completa que les confiere una nueva significación. Lo abstracto es lo indeterminado cuando se está refiriendo al punto de partida, aunque use este mismo término en el sentido de determinaciones progresivas en el proceso de producción de conocimientos. La lectura de este texto se dificulta por lo que se ha dicho antes, la utilización de una terminología clásica para referirse a conceptos nuevos. Esto mismo ocurre con el término "concreto". Marx dice que lo concreto es la síntesis de múltiples determinaciones, por lo tanto unidad de lo diverso. Aparece en el pensamiento como proceso de síntesis, como resultado, no como punto de partida, aunque sea el verdadero punto de partida, y, en consecuencia el punto de partida también de la intuición y de la representación. Obsérvese que la palabra concreto es utilizada en un mismo contexto con dos sentidos diferentes: En primer sentido, es el punto de llegada, la síntesis de múltiples determinaciones, es decir un "concreto de pensamiento" al que se llega a través del trabajo del pensamiento. En un segundo sentido lo concreto es el punto de partida, en cuanto que es el punto de partida de la intuición y de la representación. Aquí se desliza un significado de lo concreto radicalmente diferente del anterior, no es el mismo concepto, sino que el término concreto funciona como significación de lo existente, del objeto real.” p. 69. 
Enfatizó en que "El concepto de la actividad crítico-práctica es fundamental en el pensamiento de Marx" (Zuleta, 1972, p. 158). Y aunque consideró que Marx en sus escritos tempranos - como en sus tesis sobre Feuerbach - fue en ocasiones algo confuso y dio pie a posibles interpretaciones empiristas de su teoría del conocimiento, puntualizó a partir de una perspectiva propia la controvertida tesis XI, en la que Marx, para algunos, establece un parteaguas entre su propuesta práctico-crítico-revolucionaria y su crítica dialéctica a la presunta predominante postura hermenéutica de los filósofos que le antecedieron. Para Zuleta, "Marx no quiere decir que el mundo no deba ser interpretado, no quiere defender el activismo ciego, ni nada por el estilo, y así lo testimonian toda su obra y toda su práctica política. Lo que él afirma es que una crítica teórica que no sea capaz de ver los fundamentos materiales del error que critica, y de allí pasar a combatirlos, no es una crítica suficiente" (Zuleta, 1972, p. 163).

En tal sentido, el pensador colombiano deseaba diferenciar la perspectiva epistemológica de Marx y del marxismo, tanto del empirismo anterior como del entonces emergente utilitarismo y pragmatismo, que impregnarían no solo la vida filosófica británica y norteamericana, sino la de otras partes del orbe, de la cual América Latina no escaparía, no obstante sus modalidades sui generis (Guadarrama, 2004).

Ni Zuleta, ni el propio Marx se percataron de que los filósofos anteriores a este último no siempre se habían dedicado exclusivamente a interpretar el mundo, sino que también trataron de transformarlo. De otro modo no se entienden las causas de la acusación a Sócrates por su actividad práctico-pedagógica con los jóvenes atenienses, ni la esclavitud a que fue sometido Platón y su frustración ante la imposibilidad de ver realizada su República, ni el compromiso político de Aristóteles con Filipo de Macedonia y Alejandro Magno, como tampoco la praxis política y social de Tomás de Aquino, Maquiavelo, Moro, Descartes, Spinoza, Locke, Rousseau, Fichte o Hegel.

Al mismo tiempo, Zuleta quiso hacer justicia respecto al tratamiento otorgado por Lenin a la teoría del reflejo, pues consideraba que ésta constituía sin duda un lado débil de la epistemología marxista. A su juicio, "si la teoría del reflejo se queda corta no es porque sea demasiado materialista, sino porque no lo es suficientemente" (Zuleta, 1987, p. 155). A la vez, sostenía que "La teoría del reflejo plantea otra dificultad. Uno de los avances que Marx había hecho en el campo de la teoría del conocimiento, muy 
importante, era el haber acentuado la oposición entre ideología y ciencia, y el haber formulado la ideología, como esencialmente ignorante de sus fundamentos, como inconsciente, en palabras de Marx" (Zuleta, 1987, pp. 155-156). Es evidente que en este aspecto, lo cual no significa que en otros análisis descuidara tal evolución (Zuleta, 1987, p. 9), ${ }^{177}$ Zuleta no tomó en adecuada consideración la evolución de Marx y Engels desde sus trabajos iniciales a los de mayor madurez, ni tampoco la de algunos de sus más relevantes continuadores respecto al concepto de ideología.

Al mismo tiempo considerar que "También es falsa la idea de que la ideología es de clase. La ideología no es de clase. La ideología es algo consubstancial al hecho de que el hombre necesita la ilusión." (Zuleta, 2008, p. 105), puede resultar una interpretación algo romántica y por tanto distante de la concepción materialista de la historia, que en lo fundamental Zuleta compartía - al menos en otros trabajos que reconoce la existencia de la ideología burguesa (Zuleta, 1972, p. 16) ${ }^{178}$ - , pues si bien puede conducir a una especie de sociologismo vulgar reducir la producción de ideologías solamente al componente clasista, de igual modo resulta inconsistente desconocerlo o subestimarlo.

Pero independientemente de tal concepción controvertible sobre la recíproca exclusión entre ciencia e ideología, que no fue exclusiva de Zuleta, sino muy común a la interpretación prevaleciente en la perspectiva soviética del marxismo y de algunos enfoques también en el mundo occidental, como en el caso de Althusser; ${ }^{179}$ lo más significativo es la alta valoración que

177 “Tampoco voy a tomar la obra de Marx en un sentido histórico cronológico, es decir, no voy a exponer cómo pensaba Marx a los 23 años, a los 25 años, a los 30 años, cuando escribió El Manifiesto, El capital y finalmente la Crítica al Programa de Gotha. Voy a tomar el conjunto, no porque crea ni mucho menos que la obra de Marx no haya evolucionado o que Marx no haya cambiado de ideas, ambas cosas son así; evolucionó desde luego y cambió de ideas, nadie puede imaginarse que Marx puso el marxismo como una gallina pone un huevo [...]". E. Zuleta: Ensayos sobre Marx, Percepción, Medellín, 1987, p. 9.

178 "Perder de vista la diferencia esencial es el típico mecanismo con el que la ideología burguesa pretende demostrar el carácter eterno del capitalismo” Zuleta, E. Comentarios a la Introducción a la crítica de la economía política (Manuscritos de 1857) Apéndice; Sobre la teoría del reflejo. Universidad de Antioquia, Medellín. 1972. p. 16.

179 "Cuando consideraba que los trabajos de juventud de Marx eran eminentemente ideológicos y por tanto seudocientíficos según su criterio, esto presupone en cierta 
el pensador colombiano realiza de las potencialidades epistemológicas que encierra la obra de Marx. Así plantea, "El materialismo de Marx descubre las condiciones objetivas de la producción del conocimiento y también las condiciones objetivas de la producción del desconocimiento o de la ideología; un materialismo que investigue las condiciones sin las cuales una ciencia no es posible y las condiciones dentro de las cuales comienza a ser posible, y que no postula un sujeto ahistórico y asocial que observa la realidad, la aprehende allí mismo y la refleja en su cabeza. Este materialismo fundado por Marx es pues la condición necesaria para una verdadera historia de las ciencias" (Zuleta, 1972, p. 116).

La afirmación anterior evidencia que Zuleta le atribuía al materialismo histórico una dimensión y posibilidades favorecedoras de una comprensión científica de la sociedad cualitativamente superior a todas las formas anteriores de materialismo, ante todo porque se sustentaba en el análisis del papel de la división social del trabajo (Zuleta, 1972, p. 51). ${ }^{180}$ Sin embargo, le atribuye a Marx una limitada interpretación teleológica de la historia al analizar la tesis del pensador alemán según la cual:

La sociedad burguesa es la más compleja y desarrollada organización histórica de la producción. Las categorías que expresan sus condiciones y la comprensión de su organización permite al mismo tiempo comprender la organización y las relaciones de producción de todas las formas de sociedad pasadas, sobre cuyas ruinas y elementos ella fue edificada y cuyos vestigios, aún no superados, continúa arrastrando, a la vez que meros indicios previos han desarrollado en ella

forma que para Althusser no hay elementos de cientificidad en ellos, lo cual resulta a todas luces erróneo y descalificador de estas valiosas obras, que si no resolvieron todos los problemas al menos plantearon innumerables problemas sobre la enajenación, el humanismo, la articulación entre filosofía, política y religión, etc., que no solo motivaron agudas polémicas en los años que vivió el pensador francés, sino que continúan hoy día motivando la reflexión de numerosos intelectuales en todo el mundo". Guadarrama, P. "El marxismo estructuralista de Louis Althusser", en Marx Ahora. Revista Internacional, La Habana, No. 23, 2007, p. 67.

180 “(...) en Marx los conceptos de división social y división técnica del trabajo presentan una jerarquización que es fundamental para la comprensión de la concepción de Marx sobre la sociedad". p. 51. 
su significación plena, etc. La anatomía del hombre es una clave para la anatomía del mono. (Zuleta, 1972, p. 85).

A juicio de Zuleta:

Aquí hay una metáfora seductora pero poco afortunada, porque es una recaída en el evolucionismo. En realidad la anatomía del hombre solo podría ser la clave de la del mono, si el mono estuviera predestinado a ser hombre, si el hombre fuera la realización de algo que ya estuviera potencialmente en el mono. Pero esta formulación es teleológica. En realidad, en el hombre muchas cosas son desarrollos y muchas otras atrofias con respecto al mono. El hombre es una adaptación a otro medio, respuesta a otros problemas, y no el producto de la evolución de un principio interno a partir del mono. Esto mismo ocurre en la historia de las sociedades, el feudalismo puede descomponerse en capitalismo o no. Marx, para salir del historicismo cometió un error al invertir los términos del problema. Realmente, ni es cierto que para comprender el capitalismo es necesario comprender primero el feudalismo como creen los historicistas, ni es cierto que para comprender el feudalismo sea necesario comprender primero el capitalismo. El problema es otro y debe ser formulado en la siguiente forma. ¿En qué sentido los conceptos elaborados para la comprensión del capitalismo sirven para la comprensión de los sistemas anteriores? En la medida en que, a partir del estudio del capitalismo, Marx puso las bases para una ciencia de la historia elaborando conceptos de validez general, produjo un conjunto de conceptos fundamentales que permiten explicar este sistema social, y en cuanto científicos, pueden dentro de ciertos límites ser utilizados para analizar sociedades anteriores y aun sociedades posibles. (Zuleta, 1972, p. 86).

Ante tal crítica cabe preguntarse: ¿en verdad puede estudiarse un fenómeno o proceso, lo mismo en el mundo natural que social, sin tomar en adecuada consideración las estructuras y funciones de los elementos constitutivos fundamentales de las fases posteriores y anteriores de su desarrollo histórico?

No hay dudas de que en la concepción de Marx prevalece una perspectiva de la evolución progresiva de la sociedad humana heredera de las ideas de la Ilustración, pero esto en modo alguno debe identificarlo con el evolucionismo que caracterizó las ideas sociales propias del positivismo ni tampoco 
del historicismo, tan cuestionado por Popper. En Marx hay un fuerte arraigo de la visión hegeliana de la historicidad (Geschichtlichkeit) —en el sentido de concebir la historia como un devenir permanente de contradicciones de todo tipo, en el que enfatiza la lucha de clases, a diferencia del historicismo, que hiperboliza el papel de la condicionalidad circunstancial en dicho devenir-, sin que esto signifique su identificación con la perspectiva teleológica de la historia que puede observarse en Hegel.

Algunos han tratado de caracterizar a Marx y Engels como teleologistas en relación con sus ideas sobre el comunismo como superación del capitalismo (Guadarrama, 2015). Con ello desconocen sus consideraciones al respecto en La ideología alemana, según la cual este no debía ser un estado a implantar, sino un movimiento crítico superador de un estado de cosas, léase el capitalismo, y para ello debía partirse de las premisas históricas existentes. Esto significa que por supuesto no es lo mismo concebir el comunismo en Francia que en Haití. A su vez, tomar en adecuada consideración las premisas históricas existentes no significa necesariamente ser historicista, pues hasta el mismo Popper las toma en cuenta en el falsacionismo de su racionalismo crítico.

Es evidente que en las fuentes de aproximación a nuevas expresiones del marxismo se revela en Zuleta un manejo de algunos de sus cultivadores más relevantes, como Lenin, Lukács, entre otros, pero prevalece mucho más la influencia de la tradición francesa - en particular Althusser-que la teoría crítica de la escuela de Frankfurt o que algunos de sus representantes latinoamericanos.

Es sabido que Sartre - a quien Zuleta tuvo en alta estimación- pretendió completar el marxismo con el existencialismo, pues a su juicio, el primero carecía de una antropología filosófica. De forma similar Zuleta pretendió enriquecerlo con el psicoanálisis - que no solo valoró altamente en el plano teórico, sino que con frecuencia practicó- (Zuleta, 2011) para lograr un mejor esclarecimiento de los factores que intervienen en el proceso de producción de la conciencia humana.

Zuleta consideró que en los macroanálisis sociológicos y económicos de Marx sobre la sociedad capitalista, en la que se estimulan "Toda clase de 'liberaciones' y se promueven todas las ideas que obliguen a la gente a comprar. En este sentido, y no en el de un determinismo económico, el análisis de Marx que inició en El Manifiesto del Partido Comunista y desarrolló en El Capital, me parece valido en su conjunto." (Zuleta, 2008, p. 108). De tal 
modo que independientemente de que este priorizara el enfoque de lo social sobre lo individual (Zuleta, 2010, p. 201), ${ }^{181}$ se atisbaba la profundidad de su perspectiva psicológica (p. 197), ${ }^{182}$ factor este que propiciaría su confluencia con el psicoanálisis.

A partir de tales consideraciones concibió el marxismo y el psicoanálisis como compatibles y necesariamente complementarios; esto lo diferenciaba de manera sustancial de los enfoques prevalecientes en esa época en el marxismo soviético. Si Zuleta hubiera conocido algunas acusaciones ante las posibles falsificaciones realizadas por Freud en las historias clínicas de determinados pacientes con el objetivo de forzar la validación de sus teorías, tal vez hubiera modificado sus criterios al respecto.

Pero más allá de tales reconsideraciones, para el estudio que nos ocupa, que consiste en la valoración de Zuleta sobre el marxismo, lo importante es destacar su alta estimación de la cientificidad de la obra marxiana (Zuleta, 2010, p. 228) ${ }^{183}$ independientemente del mayor o menor carácter científico de la freudiana, pues para él "Cuando el psicoanálisis no se basa en una sociología histórica y dialéctica y es incapaz de una crítica social, puede derivar hacia toda clase de fantasías naturalistas, de explicaciones aberrantes y de interpretaciones reaccionarias, incluso en la obra gigantesca de su fundador" (Zuleta, 2010, p. 229).

181 "Porque superó la oposición entre individuo y sociedad, Marx no protesta contra la sociedad a nombre de una naturaleza humana idealizada, como los románticos y los utopistas, ni justifica la realidad existente como producto de una naturaleza humana originalmente dañada y que debe ser corregida por la moral y la policía, como los reaccionarios. Su crítica del hombre alienado es directamente una crítica social". Zuleta, E. "Marxismo y psicoanálisis", en Tres culturas, tres familias y otros ensayos, Hombre Nuevo Editores, Bogotá, 2010, p. 201.

182 "Es suficiente recordar el análisis de la forma mercancía para comprender que Marx descubre allí, al mismo tiempo, las leyes objetivas de una estructura económica y el campo psicológico más íntimo en que se forma la individualidad que surge bajo el dominio de estas leyes". Zuleta, E. "Marxismo y psicoanálisis", en Tres culturas, tres familias y otros ensayos, Hombre Nuevo Editores, Bogotá, 2010, p. 197.

183 "En la realidad, el sicoanálisis desprovisto de una verdadera sociología científica y de una crítica histórica rigurosa, como la que podría encontrar en el marxismo y solo en él, está continuamente amenazado por el naturalismo individualista que trata de interpretar todos los fenómenos de la vida social como una irrupción o represión de los instintos". E. Zuleta: "Marxismo y psicoanálisis", en Tres culturas, tres familias y otros ensayos, Hombre Nuevo Editores, Bogotá, 2010, p. 228. 
Por lo tanto, independientemente de sus simpatías por el psicoanálisis, que lo llevaron a practicarlo con relativa frecuencia, lo más significativo no es que pretendiera ver la posible congruencia del marxismo con el psicoanálisis, sino al revés (Zuleta, 2010, p. 202) ${ }^{184}$ Si bien a este último le atribuía la condición de cientificidad, en el primero no solo destacaba incuestionablemente este rasgo, sino que a la vez le atribuía una mayor significación teórica al fundamentarse sobre bases filosóficas mucho más consolidadas. Para Zuleta el filosofar era no solo diferente de la investigación científica, en cuanto a sus resultados y sobre todo a sus métodos, sino sobre todo constituía una forma superior de actividad intelectiva.

Una de las grandes diferencias entre Freud y Marx es que este último independientemente de caracterizarle algo sorprendente como individualista radical (Zuleta, 1987, p. 33)—— ${ }^{185}$ prestó mucha mayor atención a su condicionamiento social. "Marx se refiere siempre a individuos socialmente determinados y no al individuo y a la sociedad o a las relaciones de los individuos con la sociedad. Estudia la forma social de existencia de los individuos", afirma el pensador colombiano (Zuleta, 1987, p. 40), pues considera que "El mito roussoniano queda en evidencia; es más, Marx demuestra que solamente en sociedad el individuo puede aislarse" (Zuleta, 1987, p. 42). Al respecto se refiere a su error inicial al haber hiperbolizado el papel del individuo durante los primeros estadios del desarrollo humano, reconocido por el propio filósofo alemán (Zuleta, 1987, p. 44). ${ }^{186}$

Lo que más estima es que, en lugar de prestar atención a los hechos aislados dialécticamente, le preocupan más las concatenaciones, los nexos,

184 "Lo que hay que saber es si los descubrimientos de Freud y su exploración sistemática de una nueva dimensión de la existencia humana, son incompatibles con la concepción marxista del hombre o si, por el contrario, la corroboran, la enriquecen y permiten avanzar cualitativamente, sin renegarse, en la comprensión de la realidad." Zuleta, E. "Marxismo y psicoanálisis", en Tres culturas, tres familias y otros ensayos, Hombre Nuevo Editores, Bogotá, 2010, p. 202.

185 "El rasgo propio, característico y, por decirlo así, el acento personal del pensamiento de Marx, tal como se manifiesta desde sus primeros escritos hasta las últimas obras y se conserva a través de una compleja evolución intelectual, es su individualismo radical”. Zuleta, E. Ensayos sobre Marx, Percepción, Medellín, 1987, p. 33.

186 “Cuanto más lejos nos remontamos en la historia, tanto más aparece el individuo [...]".En este punto Marx se equivoca, y es interesante observar que su error lo lleva a formular el problema en términos de la robinsonada previamente criticada por 
los vínculos, pues: "En síntesis, para Marx los elementos están definidos por las relaciones que tienen entre sí y no por su existencia transhistórica, como elementos aislados. El verdadero objeto de estudio son los diversos haces o conjuntos, las diversas articulaciones de los elementos y no los elementos tomados en sí mismos 'abstraídos', es decir, separados del conjunto. Si para la teoría clásica de la abstracción lo común es lo esencial; para Marx, lo diferente, es decir, las diferentes formas de articulación de los elementos, es lo esencial" (Zuleta, 1987, p. 44).

Por tal motivo, resulta cuestionable reducir la perspectiva dialéctica del filosofar de Zuleta a la antigua concepción griega, como plantea Alberto Valencia (1996, p. 44), ${ }^{187}$ cuando este mismo acucioso investigador del pensador colombiano destaca que "La afirmación de que la categoría de totalidad está implícita en los más diversos análisis de Zuleta quiere decir que su pensamiento, en sus principios constitutivos fundamentales, tiene una relación muy estrecha con el pensamiento de Marx" (Valencia, 1996, p. 129). Resulta indudable que la profunda admiración del filósofo colombiano por este último no se reducía a motivaciones ideológicas, si bien estas no estaban ausentes, sino ante todo por la maciza construcción teórica afianzada especialmente en su método dialéctico (Valencia 1996, p. 133), ${ }^{188}$ muy distante y distinto al de los griegos, no solo por haber sido desarrollado por Hegel, sino por Descartes (Oizermann, y otros, 1980), Spinoza (Colectivo de autores, 1981), Rousseau (Vollpe, 1967), Helvecio y Kant principalmente, quienes también dejaron honda huella en la conformación del pensamiento de Marx. Resulta válido el análisis de Damián Pachón cuando considera que:

él. La familia, resultado de la historia, de la disolución del gen y del clan, es proyectada como el origen, mientras que la tribu es deducida de esa pretendida familia originaria. Años después, al conocer los primeros resultados de la naciente antropología científica (Morgan, etc.), Marx reconoce su error”. p. 44.

187 "La preponderancia dada por Zuleta a la interpretación de textos, autores y teorías de la dinámica de su trabajo es un indicativo de que su pensamiento es profunda y estructuralmente dialéctico en el sentido que esta denominación tiene no en Hegel o Marx, sino en el pensamiento clásico griego, sobre todo en la figura de Sócrates o en la obra de Platón". Valencia, A. En el principio era la ética... ensayo de interpretación del pensamiento de Estanislao Zuleta, Universidad del Valle, Cali, 1996, p. 44.

188 " [...] una de las más importantes contribuciones de Zuleta a la interpretación de Marx fue su comprensión del método” Idem, p. 133. 
La relación de Zuleta con el marxismo fue fructífera y totalmente crítica. Por eso Zuleta se consideró un 'marxista kantiano', 'un marxista freudiano', un 'marxista hegeliano', pero en todo caso, un marxista. Sin embargo, no hay que olvidar que Zuleta no se preocupó por el marxismo, el psicoanálisis, la literatura, el arte, etc., en sí mismos, sino como herramientas para pensar un problema específico. Zuleta criticó en muchos aspectos al marxismo, por ejemplo, consideró que Marx idealizó el proletariado, despreció la pequeño-burguesía, dio demasiada importancia a la economía sobre la ideología (aunque sostuvo que en Marx no hubo un economicismo); Zuleta no compartía el concepto de alienación como lo concibió Marx, así como el asunto de la toma del poder, la negación del conflicto y la propuesta de abolición del Estado. Además consideró que si bien Marx tuvo razón en criticar la formalidad de los derechos, su concepción de los derechos humanos no fue del todo correcta, pues aún en el comunismo estos serían necesarios (Pachón, 2011, pp. 193-194).

En relación a este último aspecto, bien es cierto lo planteado por Zuleta de que "Los marxistas saben que Marx nunca se hizo ilusiones sobre el derecho, ni siquiera en las sociedades en las cuales el proletariado ya hubiera tomado el poder, como lo muestra en la Crítica del programa de Gotha" (Zuleta, 1995, p. 192).

Acertadamente el pensador colombiano apunta que: "Marx piensa que los derechos humanos están restringidos por sus condiciones de posibilidad. El verdadero problema no habría que formularlo en términos de 'el derecho a ..., sino de "la posibilidad de..."' (Zuleta, 2008, p. 102).

En particular sobre este último aspecto Zuleta, con razón, consideró que la cuestión de los derechos humanos no debía considerarse una simple táctica para la lucha por el poder político, sino algo estratégicamente esencial en la lucha de los socialistas frente al capitalismo.

Por lo que resulta plenamente válido su criterio según el cual "Nosotros defenderemos los derechos humanos para siempre, no tácticamente por ahora. No podemos aceptar la tesis de que mientras nos tomamos el poder está bien defender los derechos humanos, pero otra cosa sería cuando ya lo tengamos" (Zuleta, 2008, p. 111). Por el contrario, sí son muy cuestionables las siguientes afirmaciones: 
La democracia no pertenece a la tradición de la izquierda, y esto hay que decirlo francamente. La tradición nuestra ha estado determinada por el marxismo, que no es un pensamiento democrático. En sentido estricto, ideológico, Marx no lo era. Cuando Marx comentó los derechos humanos, confundió la ideología individualista, sensualista, utilitaria y liberal de la época con el acontecimiento mismo. Marx criticó una ideología que proclamó los derechos humanos como una expresión simple del egoísmo del mundo capitalista, del mundo burgués individualista y de paso criticó esa concepción de los derechos. (...) Dentro de la tradición marxista, la democracia es táctica. El uso ha sido claro: hablo de democracia y eso me da espacio para hacer política, pero cuando tomo el poder cierro la posibilidad de que otros hagan política, cierro el espacio (Zuleta, 1989).

En verdad, Marx y Engels no consideraron ni a la democracia ni a los derechos humanos como algo absolutamente rechazable entre las conquistas de la modernidad, por lo que, en verdad, se plantearon la necesidad de una relación más equitativa, de ahí que expresasen que: "el primer paso de la revolución obrera será la exaltación del proletariado al Poder, la conquista de la democracia" (Manifiesto del Partido Comunista). Lo que nos podría conducir a cuestionarnos la plena validez de las ideas de Zuleta al respecto (Zuleta, 2008, p. 104). ${ }^{189}$ Otra cuestión son las experiencias de la democracia y los derechos humanos en el autodenominado "socialismo real"; pero las pretensiones de ambos pensadores eran profundamente democráticas, pues aspiraban a ofrecerle mejores formas de participación a los sectores populares y en especial a los sectores populares en el ejercicio del poder político y económico.

Cuando los derechos humanos adquirieron carta de ciudadanía propiamente e iniciaron su promoción efectiva desde fines el siglo XVIII, con la Ilustración, el impacto de la independencia de las trece colonias inglesas de

189 "La conciencia será siempre combate, con los otros y consigo mismo. El pensamiento nunca se da en el vacío, sino como posibilidad de reconocimiento, rectificación, reinterpretación, refutación, confrontación. Por todo ello no es concebible una sociedad que no tenga necesidad de la libertad de conciencia, porque la conciencia ya se haya liberado. Allí falla grave y peligrosamente la crítica de Marx a los derechos humanos." Zuleta, E. Conversaciones con Estanislao Zuleta. Hombre Nuevo Editores EU. Medellín. 2008, p. 104. 
Norteamérica y la Revolución Francesa, por supuesto que encontrarían sus falaces consignas de igualdad, libertad y fraternidad, que he denominado irónicamente paradogmas (Guadarrama, 2006), algunas expresiones de resistencia en Carlos Marx.

Éste los consideraría de algún modo expresión del derecho burgués particularmente interesados en defender la propiedad privada, pues a su juicio, "Los derechos del hombre de la Declaración francesa de 1789 conocidos ahora como derechos humanos de primera generación a diferencia de los droits du citoyen no son otra cosa que los derechos del miembro de la sociedad burguesa, es decir, del hombre egoísta, del hombre separado del hombre y de la comunidad" (Marx, 1992, p. 57).

Sin embargo algunas de las consideraciones de Marx al respecto han sido o mal comprendidas, como puede ser el caso de Zuleta, o en la peor de las situaciones tergiversadas y manipuladas (Ortiz, 2207, p. 202). ${ }^{190}$

Del mismo modo que Marx consideró a la sociedad burguesa un avance en la historia de la humanidad, e incluso consideró a la burguesía como revolucionaria para la época, pues tal estimación era por supuesto extensiva también a la democracia y los derechos humanos (Guadarrama, 2016a, p.62).

Con la ironía que le era propia Marx en El Capital, somete a consideración crítica lo que denomina el "Edén de los derechos humanos innatos" (Marx, 1975, p. 214), en el que el formalismo impera tras las consignas de "libertad, la igualdad, la propiedad y Bentham" (Marx, 1975, p. 214). A juicio de Marx la verdadera igualdad no consistía en considerar de manera igualitaria los fenómenos o clases sociales desiguales, sino por el contrario en valorarlos de manera desigual y diferenciada.

Como acertadamente considera Ernst Bloch, aunque Marx haya sido un agudo crítico del carácter formal que tiene la democracia, los derechos

190 Con razón Hernán Ortíz considera que "A lo largo de toda su obra, Marx mantiene esta posición teórica de juventud que ve en los derechos humanos decimonónicos en su expresión norteamericana y francesa, un contenido de clase, donde la propiedad burguesa es el factor determinante de todos los derechos, razón por la cual estos aparecen truncados. Por esto, ellos ocultan tras los derechos abstractos del "ciudadanos" los intereses concretos del "burgués", único beneficiario de la igualdad, libertad, dignidad, fraternidad o propiedad”. Ortiz, H. Derechos humanos. Grupo Editorial Ibañez. Bogotá. 2007. p. 202. 
humanos y en especial la libertad en la sociedad burguesa, sin embargo "estaba tan lejos de ser un crítico de la libertad que, por el contrario, interpretó la libertad como un glorioso derecho humano, en verdad como la base para su propia critica de la propiedad privada. Ello explica la conclusión que extrae: no libertad de propiedad, sino libertad respecto de la propiedad; no libertad de comercio, sino libertad respecto de la anarquía egoísta del comercio no reglamentado; no emancipación del individuo egoísta respecto de la sociedad feudal, sino emancipación de la humanidad respecto de cualquier tipo de sociedad de clases. Devuelve a la libertad, en cuanto ésta se distingue de la propiedad, el prestigio auténticamente radical que le corresponde entre los derechos del hombre" (Bloch, 1974, p. 245).

No se debe pasar por alto que Marx dedicó sus tesis doctoral al análisis de las diferencias entre la filosofía de Demócrito y Epicuro en la que destacó en este último su enriquecedora concepción de la libertad. Tampoco se debe ignorar la significativa temprana influencia recibida de Kant, tanto en su epistemología al insistir la significación del papel activo del sujeto en el proceso del conocimiento, como en su ética, reconocido acertadamente por Zuleta (2008, pp. 112-113). ${ }^{191}$ Althusser, destacaría la huella kantiana en la formación filosófica del joven Marx, especialmente orientada al análisis de la libertad humana.

Una postura algo similar de la demagogia de los derechos humanos la observó Federico Engels en el caso de "el carácter propiamente burgués de esos derechos del hombre que la Constitución americana -la primera que los ha conocido - confirme simultáneamente la esclavitud de las gentes de color existente en América: mientras se condenan los privilegios de clase se santifican los de raza" (Engels, 1965, p. 109). En la célebre Constitución de Filadelfia se abogó mucho por los derechos de los hombres, pero se ignoró por completo la esclavitud de los negros, tal vez por no considerarlos miembros de la especie humana en el sentido aristotélico de animales parlantes.

191 "El marxismo a mi juicio, es una ética, además de ser un intento bastante exitoso en algunos momentos, de alcanzar un cierto nivel de cientificidad. Es ética porque propone valores directamente como ejemplo la igualdad, la reciprocidad, la libertad, etc. En ese sentido es una ética emparentada con la ética de Kant, solo que; Marx le agrega muchas cosas más." Zuleta, E. Conversaciones con Estanislao Zuleta. Hombre Nuevo Editores EU. Medellín. 2008. pp. 112-113. 
Por otra parte, llama poderosamente la atención que Engels, en la "Crítica del Programa de Erfurt" de 1981, utilizando precisamente las posibilidades que puede ofrecer la democracia burguesa sostiene - de una forma mucho más diáfana que en el propio Marx- la posibilidad de una vía pacífica al socialismo, cuando considera que allí "donde la representación popular concentra en sus manos todo el poder, donde se puede hacer por vía constitucional todo lo que se quiera, siempre que uno cuente con la mayoría del pueblo" (Engels, 1976, p. 455), es decir en las repúblicas democráticas.

Sin embargo, el compañero de Marx se lamenta de que "La ironía de la historia universal lo pone todo patas arriba. Nosotros, 'los revolucionarios', 'los elementos subversivos', prosperamos mucho más con los medios legales que con los ilegales y la subversión. Los partidos del orden, como ellos se llaman se van a pique con la legalidad creada por ellos mismos" (Engels, 1971, p.121).

América Latina puede demostrar la validez de tal afirmación. Son múltiples los ejemplos que demuestran que cuando los intereses de las oligarquías nacionales, en alianzas estratégicas con los poderes transnacionales e imperiales, se han visto amenazados por la posibilidad del triunfo o su efectiva victoria por vías democráticas de gobiernos con algún, aunque sea ligero, matiz socialista, se han organizado y realizado efectivos golpes de Estado de la derecha, como sucedió contra Paz Estensoro en Bolivia, Goulart en Brasil, Arbenz en Guatemala, de Batista contra Prio en Cuba, contra Allende en Chile, que establecieron dictaduras fascistoides o intentos fallidos contra Chávez en Venezuela, Morales en Bolivia, Correa en Ecuador, y finalmente la modalidad de golpes de Estado "blandos" contra Zelaya en Honduras, Lugo en Paraguay, Dilma en Brasil, entre otros.

La identificación de Zuleta con el marxismo no se debe solo a su reconocido rigor teórico, sino también por motivos ideológicos, especialmente por su humanismo (Guadarrama, 2011, pp. 313-332) y por presentar críticas alternativas históricas (Valencia, 1996, p. 131) ${ }^{192}$ esperanzadoras de superación de las enajenantes relaciones económicas que el capitalismo impone.

192 "Su lectura de Marx no es, pues, propiamente estructuralista sino 'humanista', 'historicista', o si se quiere simplemente crítica". Valencia, A. En el principio era la ética... ensayo de interpretación del pensamiento de Estanislao Zuleta, Universidad del Valle, Cali, 1996, p. 131. 
De ahí que declarase: "El marxismo nos ha satisfecho mucho. No nos alegremos de eso. Nos ha satisfecho porque nos ha dado la última gran teoría en la historia que le ha dado al hombre una meta; le ha dicho para dónde va. Desde luego, no es muy cómodo perder esa satisfacción y ver que hay muchas interrogantes. Sin embargo, a mi juicio, la crítica que hizo Marx de la sociedad capitalista, por lo que esta sociedad había producido como posibilidades humanas y por lo que impedía de realización del hombre, es esencialmente correcta” (Zuleta, 1987, p. 32).

Zuleta se percata de que más que descubridor de una teoría general de toda la evolución humana - que el propio Marx modestamente consideraba era atribuirle méritos indebidos- él planteó acertadamente en su obra, especialmente en El capital, las claves principales para una adecuada comprensión de los elementos esenciales de la sociedad capitalista, al menos hasta la época que le correspondió vivir al pensador alemán. Pero a su vez, éste descubrió tendencias generales del desarrollo de esta formación económico-social, así como algunas en las que le antecedieron, sin que esto implique convertirlo en un especulativo filósofo de la historia más, como lamentablemente intentaron presentarlo algunos de sus continuadores. Algo que era desaprobado por el propio Marx cuando con modestia respondió que él no había descubierto las leyes universales de la historia, sino solamente la génesis y desarrollo del capitalismo exclusivamente en Europa occidental.

En varias ocasiones Zuleta dejó claramente sentada su posición, tanto filosófica como ideológica, en relación con este aporte del pensador alemán al considerar "La obra de Marx es una crítica fundamental de la civilización capitalista. Estar en contra de Marx muy frecuentemente suena como estar a favor del capitalismo. Estar a favor de Marx, sin duda alguna, es estar en contra del capitalismo, no tengo que ocultar ninguna carta, estoy en contra del capitalismo" (Zuleta, 1987, p. 55).

A su juicio, "El marxismo lleva a cabo una crítica muy radical del orden capitalista que se refiere, no a una forma determinada de propiedad, sino a la propiedad como tal, definida por supuesto, en términos marxistas como diferentes formas históricas de derecho al plustrabajo" (Zuleta, 1995, p. 170). En ese aspecto destaca la sustancial diferencia del análisis de Marx respecto a otros investigadores que le antecedieron y sucedieron, al señalar: "Cuando Marx analiza el sistema capitalista de producción, su investigación 
difiere de los economistas anteriores y posteriores fundamentalmente en el hecho de que Marx no estudia simplemente la manera como se produce, se cambia y se consume en las condiciones capitalistas, sino la manera como se producen estas condiciones mismas" (Zuleta, 1987, p. 172).

Su optimismo epistemológico en relación con las potencialidades del marxismo en cuanto a alcanzar un mejor conocimiento del desarrollo humano, a pesar de reconocer determinados errores y limitaciones al respecto, se mantuvo siempre latente (Zuleta, 1987, p. 131). ${ }^{193}$ Especialmente rechazó cualquier tipo de interpretación determinista o teleológica de la historia que se derivara del propio Marx, como es el caso analizado de la presunta misión histórica del proletariado, que de algún modo pudiese limitar la concepción sobre la actividad práctico-crítico-revolucionaria, tan inherente al marxismo más auténtico (Guadarrama, 1999) y por tanto, la libertad humana (Zuleta, 1996, p. 132).

El pensamiento de Zuleta se articula en cierta medida con la tradición humanista, desalienadora y contrahegemónica que ha sido común a la tradición del filosofar latinoamericano, aunque no se aprecia en su obra un manifiesto conocimiento de sus representantes. Su postura ante el marxismo como concepción del mundo, como método, pero también su componente ideológico, lo aproximan a aquellos heterodoxos que se apropiaron de esta teoría no para construirle un altar, sino para utilizarla en todo lo valioso posible, pero a la vez para desarrollarla en circunstancias nuevas que el pensador de Tréveris jamás imaginó.

En tal sentido, Zuleta asumió de Marx lo más valioso, su optimismo epistemológico y escepticismo creador orgánicamente articulado con una

193 “El marxismo podrá construir una nueva antropología y liquidar sus ilusiones? ¿O no podrá? Yo creo que podría hacerlo, liquidando su ilusión de que vamos encaminados por no sé qué mecanismo histórico hacia una fiesta final. Liquidar también la idea de que la sociedad pueda ser armónica, no conflictiva, sin leyes, sin gobierno, sin nada, porque ya no habrá propiedad privada. El vigor de la crítica marxista a la sociedad capitalista debe ser acentuado y debemos ser conscientes de la crisis de nuestra sociedad, no solo del modo de producción, sino de las relaciones humanas más elementales entre los hombres y las mujeres, los niños y los adultos, y los hombres con su propia muerte, su pavor a la muerte y a la ancianidad. ¿El marxismo podrá enfrentar eso? No lo sé. Sé que plantear esta cuestión es pensar el marxismo como algo que no nos ha dado solución. Sé que eso es molesto". Zuleta, 1987, p. 31. 
praxis intelectual profundamente comprometida con la crítica al capitalismo y a cualquier forma de sociedad enajenante.

Tal vez lo más marxista de Zuleta fue asumir con rigor aquella indicación del generador, junto a Engels, de la concepción materialista de la historia: dudar de todo y revelarse contra todo tipo de nueva edición del escolástico principi autoritaris. Por eso se distanció de la militancia del partido comunista, sin que esto significase que se distanciase de su identificación con el socialismo. Fue en última instancia más una ruptura política que ideológica. Y continuó con quijotesca vehemencia su apostolado filosófico para tratar de despertar en la juventud el espíritu creativo que debe enaltecer la práctica teórica para revertirse adecuadamente en la transformación de la sociedad, y así evitar cualquier tipo de activismo político irreflexivo.

Al criticar la manipulación que se lleva a cabo en la lucha ideológica de la educación fundamentalmente universitaria con la intención de justificar una presunta eternidad del capitalismo y, por tanto, de desacreditar cualquier tipo de promoción de las ideas revolucionarias, Zuleta plantea:

Los marxistas no tienden a formular esta clase de lucha porque naturalmente hay otras luchas válidas que son más inmediatas, ciertamente. Pero si tenemos una perspectiva de transformación social a largo plazo, y nos proponemos luchar contra la dominación ideológica en todos sus aspectos, no debemos dejar a ninguna ciencia tranquila. Debemos preguntarle a cada una por sus efectos sociales, sus modos de producción, sus modos de neutralización, su forma de transmisión. Debemos reconocer que estamos situados en un ámbito donde se ha separado el trabajo productivo de la adquisición de conocimientos. Nuestra crítica puede colaborar para que las luchas actuales sean más eficaces y más profundas, cualesquiera que ellas sean. (Zuleta, 1995, p. 196).

Esta afirmación evidencia que la labor académica de Zuleta, además del requerido rigor teórico, constituía simultáneamente una forma de colaboración en el enriquecimiento ideológico de las nuevas generaciones para la lucha por una sociedad más humana y, por tanto, superadora de las injustas relaciones y formas de dominación imperantes en el capitalismo.

Por tal motivo, las reflexiones teóricas de Zuleta en relación con la filosofía y el marxismo fueron profundamente auténticas. Si fueron o no originales, 
de eso se ocuparán otros investigadores, pero la cuestión resulta secundaria, pues lo más importante es la correspondencia con las exigencias epistémicas que tuvieron con la sociedad colombiana y latinoamericana de su tiempo y la trascendencia que continúan teniendo en el presente. 
Capítulo XII 
